
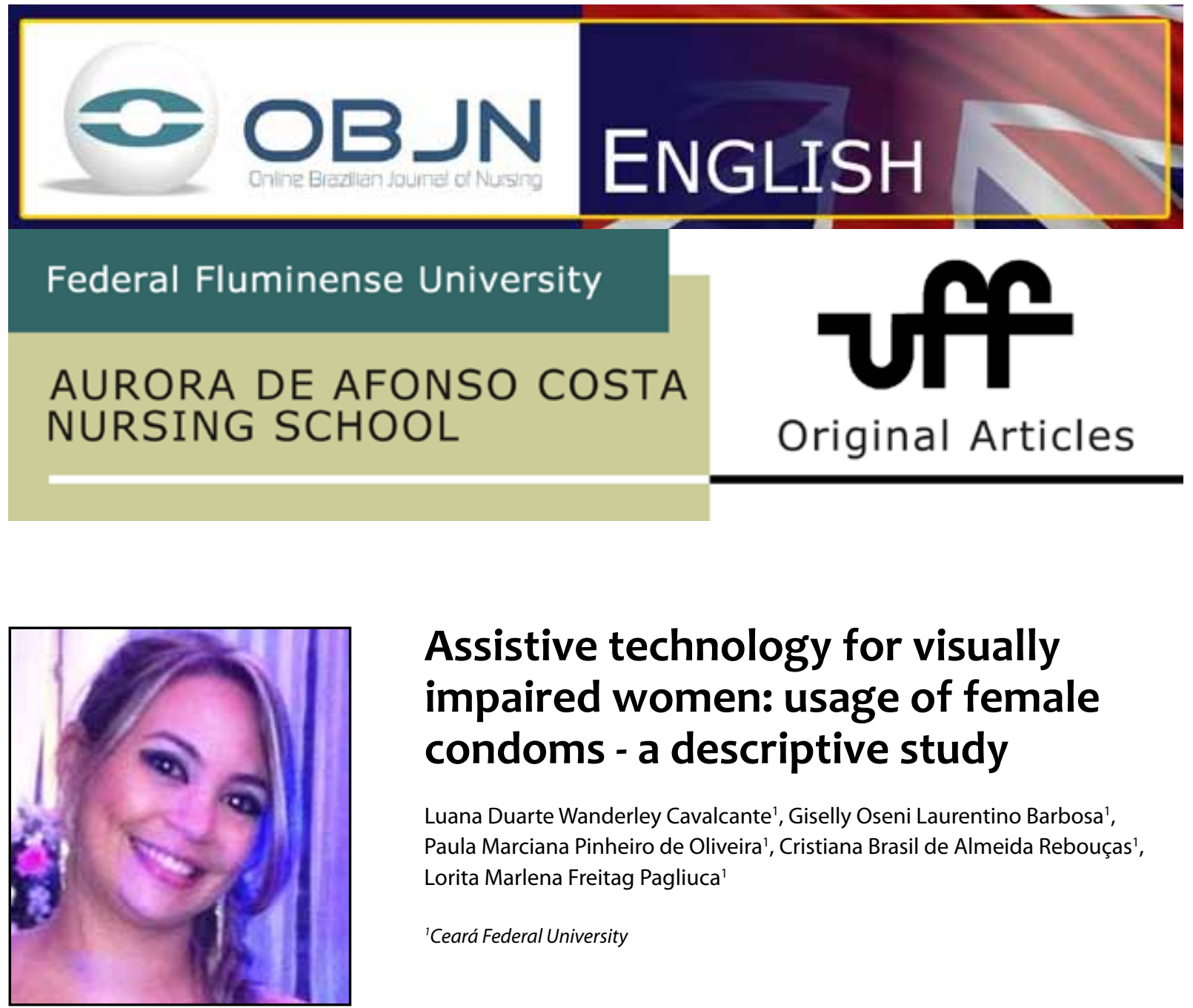

\title{
Assistive technology for visually impaired women: usage of female condoms - a descriptive study
}

\author{
Luana Duarte Wanderley Cavalcante', Giselly Oseni Laurentino Barbosa', \\ Paula Marciana Pinheiro de Oliveira', Cristiana Brasil de Almeida Rebouças', \\ Lorita Marlena Freitag Pagliuca' \\ ${ }^{1}$ Ceará Federal University
}

\begin{abstract}
Aim: To develop an Assistive Technology for visually impaired women to learn how to use the female condom. Method: This is a descriptive and exploratory research, with a qualitative approach. Three workshops were held between April and May 2010. These events were recorded and the statements were transcribed and analyzed by the content analysis method. Results: The technology developed was written educational material, the manufacture of a female prosthesis, training on the placement of the condom in the prosthesis and workshops. The data was organized into three categories. Visual impairment did not inhibit the construction of the prosthesis.

Discussion: Mistaken comments and doubts emerged during the placement of the condom in the prosthesis which evidenced women's lack of understanding about the condom.

Conclusion: The technology developed was able to effectively assist women's needs regarding the issues addressed, as it helped to inform women with regards to STD, female anatomy, and the creative, interactive and effective use of the female condom.
\end{abstract}

Descriptors: Visually Impaired Persons; Technology; Nursing. 


\section{INTRODUCTION}

According to the Division of Documentation and Information of the Benjamin Constant Institute, to be considered as a visually impaired person, the individual should be completely blind or with a low visibility range. The first definition refers to the person that has an impairment ranging from a complete lack of vision to the loss of the perception of luminosity; while the second ranges from the capacity to feel the difference in luminosity up to the level that the visual impairment interferes or limits the person's general performance ${ }^{(1)}$.

In the area of health, the visually impaired person has some difficulties obtaining access to information, especially regarding sexual and reproductive health, as they require a different approach. The literature mentions the difficulty of impaired youngsters in exercising their rights and searching for autonomy through effective social inclusion and participation. Among these rights, is the right to exercise their own sexuality ${ }^{(2)}$.

Society does not recognize that impaired people have feelings linked to affective and sexual needs; this limits their possibilities in life and creates a relationship of "non-person" to the development of sexuality. The impaired individual is considered to be an asexual being, or of incomplete sexuality, without any affective-sexual perspectives or desires. The lack of recognition of their sexuality is reflected in a consciousness of individuals that must be disciplined, isolated, protected and infantilized ${ }^{(2)}$. This denial of the sexuality of the impaired person either at home, at school or at the health service location, besides generating disinformation and prejudice, coincides with the rise in the exposure of these individuals to the risk of infection by Sexually Transmitted Diseases (STD), for example, the Acquired Immunodeficiency Syndrome (AIDS) ${ }^{(3)}$.
Recognizing the universality of sexuality and the limited assistance directed to the visually impaired person, the occurrence of STD among this clientele is relevant. A study shows that the Impaired Person (IP) has twice the risk of being infected by the Human Immunodeficiency Virus (HIV), if compared to the rest of the population ${ }^{(4)}$.

Women have searched for new methods to prevent and take care of their health. The female condom is one of the most recent, and possibly, the most important female alternative to prevent STD and to protect against undesired pregnancy. However, there is a resistance to the use of this instrument due to the lack of dialogue or previous agreement of the couple. This factor reinforces the pertinence of effective action that deals with the importance of the condom in the fight against STDs, making it widely known among the population and strengthening the adherence to their use, reinforcing the question of prevention by the use of the condom as a conscious format to exercise sexuality in a pleasant and safe way, avoiding the spread of STD ${ }^{(5)}$.

For people with disabilities there is a need to use Assistive Technology (AT). This is a recent terminology used to identify the complete set of resources and services that contribute to provide or amplify the functional abilities of people with disabilities and the elderly. Its main goal is to provide the disabled person with a higher level of independence, better quality of life and social inclusion through the expansion of their communication abilities, mobility, self-control over the surrounding environment, general abilities, work, and integration with family and society ${ }^{(6)}$.

It is the nurse's responsibility, as the health professional who works directly to promote and educate the whole population, to develop strategies aimed at empowering the individual and visually impaired people collectively, in order to improve the quality of life of this clientele $e^{(7)}$. 
Hence, the objective of this study was to develop an AT for visually impaired women to learn how to use the female condom, in order to prevent the spread of STD.

\section{METHOD}

This is a descriptive, exploratory study with a qualitative approach. Three workshops with visually impaired people took place between April and May 2010, on dates scheduled according to the availability of the subjects. According to literature, the workshops are characterized by the participative construction of the content and of the learning process, with an exchange of experiences and information among the participants. The facilitator of the process works as a support to remove doubts and direct the discussions. The workshop can be preceded by the preparation of material, or it can be built by the subjects involved in the event ${ }^{(8)}$.

The subjects of this study were visually impaired women, sexually active or inactive, all above 18 years old. They were contacted after a random selection based on the data bank of visually impaired people, organized by the Project Impaired Person: investigation of nursing care (original title is Pessoa com Deficiência: investigação do cuidado de enfermagem, in Portuguese). This study was developed in the Laboratory of Communication in Health (LabCom_Saúde, in Portuguese), of the Department of Nursing, at Ceará Federal University. This department gathers equipment and infrastructure for individuals and collectivites, with a register of sound and images for the experiments.

A text using rimed verses was created to explain the main STD and family planning, and explain the use of the condom. During the first workshop this text was fully read without interruptions. After that, it was re-read, pausing to discuss parts of it and resolve doubts. During the second workshop, prosthesis of the female genitalia was created. The tactile materials used were dishwashing sponges $(109 \mathrm{~mm} \times 73 \mathrm{~mm}$ $x 20 \mathrm{~mm}$ ) and rubber bands. Each participant received two sponges and three bands, and the instructions to build the instrument were given orally. The guidelines were: 1) put together the larger sides of the sponges, making a rectangle, and if you prefer, keep the two sponges together as they come originally in the package; 2) put together the two shorter sides of the rectangle, making a tube, leaving the soft side inside and the rough one out and; 3 ) involve the tube with an alloy in each edge and one in the middle, so the tube stays firm and strong. In the last workshop each person in the study used the prosthesis of the female genitalia to place the female condom.

The evaluation of the study was done through a process of observation of the three workshops. At the end of the activities a formal and individual evaluation was done, based on an instrument that fulfills the requisites of education in health to the visually impaired, as seen in previous studies $^{(9-10)}$. It was adapted to the particularities of this study. The workshops were recorded and the conversations were transcribed and analyzed qualitatively by the method of content analysis. This method is based on a set of techniques of analysis in communication, not only focusing on the study of the language or linguistic, but also on the less precise partial determination of the conditions of text production, which is the object of the methodology ${ }^{(11)}$. The analysis was not divided by the workshops. This project was approved by the Ethics in Research Committee (COMEPE, in Portuguese), by Ceará Federal University (UFC, in Portuguese), under registry 312/09. The individuals that agreed to participate in this research signed a Free and Clear Consent Agreement in the presence of an eyewitness. 


\section{RESULTS}

Seven women participated in this study between 19 and 32 years old. Among them, one is married, three have 'law marriage' status and three are single. All participants reported a sexually active life. Their educational level varied from an incomplete Middle School level to a full Bachelor degree. Among the participants of this study, six are fully blind and one has low vision. Five have been visually impaired since birth and two became blind during adulthood. One of the participants has a singular characteristic: she became blind when studying in College for a career in Health, but she was not able to conclude her studies due to her recent condition. For this study, the subjects were renamed as DV (acronym for Deficiente Visual, which, in Portuguese, means Visual Impaired Person) 1 to 7.

For the first workshop a technological resource was created: a text, with rimed verses, called For the STD to be gone, let's use the condom (Para DST evitar, camisinha vamos usar, in Portuguese), dealing with the main STD and family planning, and directing the use of condoms. In this workshop the text was read directly and this was followed by a second reading with pauses, with subsequent debates to clarify the information provided.

During the second workshop, prosthesis of the female genitalia was built by the subjects, under the supervision of the facilitator. This was called Prosthesis of vaginal canal, made with sponges and rubber bands, in order to simulate the vaginal canal. All participants were able to produce the prosthesis successfully.

In the third workshop, the participants were taught to place and remove the female condom in the Prosthesis of vaginal canal that each participant had built in the last workshop. The instructions for how to use the female condom were based on the guidelines of the Brazilian Ministry of Health ${ }^{(12)}$ and adapted for the visually impaired clientele. All participants were able to place the female condom in the prosthesis.

At the end of the activities a formal and individual evaluation took place through an adapted instrument. It is possible to consider the whole set of activities developed in this study as an AT, which comprises a written educational material called For the STD to be gone, let's use the condom, the construction of the prosthesis of the female genitalia, and the modality of the workshops.

The data analysis was organized into three topics, which were grouped in four categories related to the answers given by the subjects. The topics were not divided by each workshop. The first topic was called (1) Usage of the educational written material For the STD to be gone, let's use the condom, and presented two categories (1.1). The discussion regarding STD and (1.2) Evaluation of the written material For the STD to be gone, let's use the condom. The second topic was called (2) Construction of the female prosthesis and placement of the condom, with the categories (2.1) Experience in building the prosthesis and (2.2) Female condom in the Prosthesis of vaginal canal. The third topic was called (3) Formal evaluation of the AT.

Topic 1: Usage of the educational written material For the STD to be gone, let's use the condom

From the written material produced, this topic represents the understanding of the visually impaired women regarding STD, their doubts and comments learned in their family environment and in society, and the evaluation of the written material based on the opinion of these women.

In this topic two categories arose: the discussion about STD and the evaluation of the written material For the STD to be gone, let's use the condom. 
teach sexual health in a school and use a language more close to Medicine, no one

A discussion of the theme of the research was proposed, to motivate the participation of the women and to create a dialogue between the group and the facilitator. This category refers to the understanding of the participants and their comments and doubts regarding STD, reported during the discussion of the educational written material, such as:

In the case of herpes zoster, it is not an STD; it is a virus that we have inside of us and when we have low immunity, the disease comes up, but it is not an STD. We see some blisters, some secretion and it's transmissible, with similar symptoms... I've already heard of cancroid... Diabetic women are more suitable to develop candida? (DV 3)

It was observed that the person who participated the most during the discussion was the visually impaired person that had undertaken half a course in the area of health (DV 3), so it is assumed that she had learned a greater part of her understanding of STD in College. This was different from the other women who barely put forward an opinion, maybe due to the lack of, or little, knowledge of the topic. All doubts and comments were clarified at this point.

Category 1.2: Evaluation of the written material For the STD to be gone, let's use the condom

This category characterizes the critical evaluation done by the visually impaired women regarding the written material For the STD to be gone, let's use the condom. These women reported the following:

I loved it, it was very clear for everybody. I liked the language, the way it was used; it was really cool because if you are going to will understand anything. (DV 4)

The text was very creative, simple, easy to understand. (DV 2)

The women in this study reported that the written material was adequate in the language used, the content presented and the approach used.

Topic 2: Construction of the prosthesis and the placement of the condom

This topic demonstrates the experiences of the women during the construction of the Prosthesis of vaginal canal and during the use of this prosthesis to train them in the location and the removal of female condom. There were some comments, doubts were clarified and their experiences were reported.

In this topic, two categories emerged: the experience in building the prosthesis, and the female condom in the Prosthesis of vaginal canal.

Category 2.1: Experience in building the prosthesis

This category embraces the comments and doubts during the construction of the prosthesis and the experiences reported by the women in the research.

What is the color of the sponge?... It is infected by some STD, because it's yellow! (laughs) (DV 3)

Creative and interesting; I never thought that through a sponge we could to that... (DV 5) 
It was seen that the experience of building the prosthesis was interesting enough for the women, who demonstrated enthusiasm and had many laughs during the construction.

\section{Category 2.2: Female condom in the Prosthesis of the vaginal canal}

This category represents the doubts and comments reported by the women during the use of the prosthesis with female condoms.

To use the prosthesis, the participants followed the instructions in how to place the female condom. The first instruction was to check the expiration date on the package, but it was not adapted to Braille, therefore visually impaired women need to find this information with a sighted person, which may lead to a certain amount of embarrassment. Based on this fact, some participants made some comments, such as:

\author{
They must put [the expiration date] in \\ Braille too! (DV 1) \\ I'm going to ask my mother: Mom, check the \\ date for me, please! (laughs) (DV 3)
}

After this issue, questions and comments arose during the placement of the female condom, such as:

\footnotetext{
I read in a magazine that after using the female condom, you can wash and use it again; is it true? (laughs) (DV 1)

Is the uterus this size? (pointing to the smaller ring of the condom) (DV 6)
}

The interest of the women in learning how to use the female condom was noted. All doubts and comments were resolved.

\section{Topic 3: Formal evaluation of the AT}

This topic covers the evaluation of the visually impaired participants, through an instrument previously described, about the technology developed, which is composed not only of the educational written material and the prosthesis of female genitalia, but the whole process of teaching and learning included in the three workshops.

With regards to the items the technology contributes and stimulates the learning and the technology motivates the autonomy as it was built by the user, the women reported that the technology developed contributes to learning and provides autonomy, as it motivates women to know themselves better and makes the individual more independent.

$$
\begin{aligned}
& \text { It contributes to the learning because it is } \\
& \text { difficult to talk about that at home. (DV 4) }
\end{aligned}
$$

\begin{abstract}
For sure it's an instrument for self-learning because there are people that do not touch themselves. It works as a stimulus. There are women who are ashamed and this can give them some autonomy to change that. (DV 5)
\end{abstract}

With regards to the question seen in the item the technology can correspond to the level of information of a wider public, the participants mentioned that the technology is simple and can be transmitted to any person.

It can [be used] because it's very simple, easy to learn and teach, you can use it in all [social] classes. (DV 5)

It corresponds [to the final purpose], because the material used is commonly found everywhere and it's very simple too. (DV 6) 
With regards to the fact that the technology highlights the importance of the usage of condoms among visually impaired people mentioned in the item that says the technology stresses the importance of the practice which is designed for blind people, women have reported that the technology is one way to motivate the use of female condoms among visually impaired people and sighted people. Furthermore, it motivates self-awareness.

It is a way to motivate the use of condom, to motivate women to know themselves a little better, because there are women that are ashamed to know themselves, to touch themselves... It is another way to avoid diseases or even a baby (unplanned pregnancy). (DV 5)

In regards to the item the technology arouses interest and curiosity, the visually impaired women argued that the technology performed just as expected, as it is reported:

It creates some curiosity to understand how it is, as we don't know our bodies so well... (DV 6)

It does arise some curiosity; in fact l've used [the condom] already, and it worked just fine, and sometimes it's good to use it because there are men that they don't like to use their condoms, so then the woman has to use it... the public clinics should motivate by giving some female condoms. (DV 7)

With regards to the question of the usage of the technology on the Internet, a topic mentioned in the item the technology is adequate and can be used as a tool for distance learning education in health, there was not a single view in the answers given. The arguments were:
It is possible, but you will need a sighted person to help, but it would help in sexual orientation. Through the Internet, by yourself, I don't think it will work. (DV 1)

You can do it by yourself, in the same way you work yourself out to cook, to light the stove, you can find a way to build that up. Nothing is impossible for the blind. (DV 7)

With regards to the items the technology is adapted to the target audience and the technology does not reflect any type of discrimination or prejudice, all women reported that the technology built is adapted to the visually impaired public and it does not reflect any type of discrimination or prejudice.

Based on the material used to build the prosthesis, as observed on the item the material used in the prosthesis is adequate, the women responded that:

It's made of simple, cheap material. (DV 2)

... it has the same elasticity of the real vaginal canal... (DV 5)

According to the majority of women, the material in the prosthesis is adequate and it represented the elasticity of the vaginal canal well.

Concerning the item the instruction is accessible, the women in the study evaluated and reported this to be at an adequate level.

Yes, it was practical. The way it was taught is very important. (DV 5)

No doubt about it. If we were in a public clinic, no one would explain that well, and you did it very well. Or they don't explain anything, or they explain it roughly. The people there are not worried in explaining 
things well; in health, you should learn how to take care of blind people, you should learn how to talk without using difficult words and how to deal with us. (DV 4)

Visually impaired women also reported that, in relation to the item the time consumed was enough for the activities proposed, the timing was sufficient to make everybody to understand, and that in the item the workshops stimulated the learning process, the approach used with the group was interesting, as they could share their own experiences.

\section{DISCUSSION}

According to the analysis of the data, in the first topic, we observed that in the category "Discussion of STD" there was little talk or discussion about the issue. It is worth remembering that there were a significant number of doubts present in their discourse. In a previous study, regarding the sexuality of visually impaired teenagers, a great deficit in understanding and a good amount of erroneous information about the ways of transmission and contamination of STD was observed; during their discourses the data seemed confusing, filled with vague and diffuse ideas regarding the question ${ }^{(13)}$. We can see the importance of transmitting understanding of STD to the visually impaired clientele.

It is important to highlight that visually impaired people have the same potential to develop risky health behavior, because besides having distinct needs, they have the same limitations as any other human being ${ }^{(14)}$. Such risky behavior is based on the level of understanding of visually impaired people in sexual education, influenced by the social environment in which they live. This also is reflected by the limited materials available adapted to teach sexual orienta- tion to this clientele ${ }^{(7)}$. Therefore, as nursing is a science that works in the process of caring, it is the nurses' responsibility to develop resources that assist the transmission of information to visually impaired people, so that they can become more independent with regards to self-care ${ }^{(13)}$.

Still in relation to the first topic we observed that the category Evaluation of the written material For the STD to be gone, let's use the condom was evaluated positively. In a comment about the written material from a visually impaired woman, she mentioned that the language was adequate because everyone could understand and also the text had no technical terminology, which according to her is "medicine language". It can be seen that the language of health professionals, when explaining things to the client, must be clear in order to establish good communication between the nurse and the patient. Literature affirms that the process of communication must be efficient and suited to the requirements of each person in order to permit human assistance ${ }^{(15)}$.

In relation to the second topic, we have analyzed the category Experience in building the prosthesis, in which one participant showed that she had learned about the proposed topic when she made a joke about the color of the sponge, saying it was contaminated by STD because of the yellow color. The effective participation of women in building the prosthesis within which to place the condom promoted a greater interest on the part of these women. The lack of sight was not an impediment to building the prosthesis, as all of those involved were successful in building the proposed model.

In relation to the use of the prosthesis and the second topic, the category Female condom in the Prosthesis of vaginal canal, it was noted that the instructions of the Brazilian Ministry of Health on how to use the female condom were not adapted to visually impaired women. For 
example, it mentioned 'Open the envelope by the side indicated by the arrow', we would ask how will a visually impaired person know how to proceed? Furthermore, on the packaging of the female condom there is no expiration date printed in Braille, which demands that the visually impaired person asks a sighted person for the information needed. In this case, the visually impaired may end up preferring to have sexual intercourse without protection to avoid extra, unnecessary constraints. There is a clear necessity to develop more accessible material for visually impaired people. According to some studies, the area of health lacks sexual orientation programs adapted to the visually impaired, with material written in Braille and that may use other senses, as the use of vision is not the only way to transmit and share information ${ }^{(13)}$.

Mistaken comments and many doubts arose during the placement of female condom, leading to the idea that these women had little information regarding the proposed theme. Literature mentions that health services must be prepared to offer education in health that includes the concepts of special education, and material and methods adapted to the impaired clientele $^{(14)}$. Male condoms are more popular, and therefore their use is more common, but on the other hand, it is necessary to disseminate the use of female condoms so that women can use them and obtain protection against STD. A previous study shows that the majority of the Brazilian population with an active sexually status know of male condoms, and if there is a necessity to create a mass behavior, it must first of all be well known ${ }^{(5)}$.

On the third topic, Formal evaluation of the AT, it was observed from the item the technology contributes and stimulates learning that one volunteer mentioned the question of the difficulty of talking about sexuality at home. When parents deal with the sexuality of their daughters and sons well dialogue ensues and it is possibile to establish safe boundaries. However, the sexuality of the youngest generation represents a challenge to parents. What is currently normal among impaired youngsters is that their sexuality is either ignored, as if they were asexual, or it is said to be too sharp and needing external control ${ }^{(4)}$.

In relation to the item the learning and the technology motivates the autonomy as it was built by the user, the women reported that the technology can provide autonomy, permitting the visually impaired to become more independent. According to the participants, with regards to the item the technology can correspond to the level of understanding of a wider public, the technology was rated as simple and it can be transmitted to any person.

There is a connection between the items motivates the autonomy by being built by the user and highlights the importance of practice destined to blind people, in which there were reports of self-understanding, the shame women feel in touching and knowing themselves, and the importance of being motivated. A study reveals that there is a relative lack of intimacy among women in regards to their own body, possibly due to cultural questions ${ }^{(5)}$; the impaired woman is seen as a person unable to exercise her own sexuality $^{(2)}$. It is necessary to motivate visually impaired women to know their own bodies through touch so that they can interpret their own sexuality.

In the item the technology arouses interest and curiosity, women reported that they were curious to understand how the female condom was placed, however one of them mentioned that she had used the condom previously and that some men did not like to wear the male condom, thus leaving the woman with the responsibility of using the female one. With regard to the usage of a barrier method during sexual intercourse, a study mentions that the nego- 
tiation between the partners about the use of condoms is one of the most difficult issues dealt with by women ${ }^{(5)}$. The fact that the partner does not like to wear the condom and the trust that women place on this makes the women adopt sexually risky behavior ${ }^{(7)}$.

According to literature, an important advantage of the use of female condoms is that the women can include herself in the decision to use condom, increasing her power to deliberate and express interest in having protected sexual relationships. Today, one of the characteristics of the AIDS epidemic in Brazil is the 'feminization', and in this context, the use of female condoms has a significant importance ${ }^{(5)}$.

Based on the information shared about the item the technology is adequate and it can be used as a tool for distant learning education in health, there were some disagreements among the visually impaired present in this study. Some discussed that visually impaired people will not be able to position the Prosthesis of the vaginal canal by following the instructions on the Internet themselves, but only with the aid of a sighted person at their side. Others mentioned that this is a task that can be done by visually impaired women without any additional help.

Nowadays many visually impaired people have access to the Internet. Through this media, many new opportunities to transmit information and knowledge in an organized, fast and effective way have emerged, enabling access by people that live in places with a high educational deficit ${ }^{(16)}$. We believe that access to educational technology through the Internet can contribute to the development of better sexual health of visually impaired people, different from their current situation. Experiences with a higher number of visually impaired volunteers related to this question, which must be considered by other studies.

In relation to the third topic, it can be seen in the item the material that composes the pros- thesis is adequate that the material used has a similar characteristic in terms of the elasticity of the vaginal canal, and it is made of low-cost elements; it was considered adequate, representing the vaginal canal well. Besides the written educational material and the discussions about STD, we tried to work with tactile material, in order to provoke a higher interest by the visually impaired women. It is recommended that the audio material should be used together with tactile material, which are strategies aimed at group inclusion and an inclusive approach, thus having teaching instruments that are accessible to all ${ }^{(14)}$.

In the item the instruction is accessible, in the third topic the women mentioned that the instructions were approached in a didactic and accessible way, as all could participate in the discussions. One of them explained that many people do not offer any explanation to visually impaired people, especially the health professionals, who according to her, do not provide a good caring service to the visually impaired in general, suggesting that these professionals spend more time learning to care for visually impaired clientele. Research reveals that the health professionals, especially nurses, are not well prepared to approach the questions linked to the health of visually impaired people ${ }^{(13)}$. Nurses should develop verbal communication skills towards visually impaired people and must know and valorize the specific questions regarding the attention of these people ${ }^{(17)}$.

Based on the discussion of the item the time consumed was enough for the activities proposed, the participants considered that the time was ideal, enough for all to understand. Referring to the item the workshops stimulated learning, the women reported that it was interesting to use a group approach to the discussions, because it led to some exchange of experiences. The literature supports the exposition of the content in 
order to create an individual or group discussion among the visually impaired and this can be an important strategy to be applied ${ }^{(7)}$.

Summarizing, the AT refers to any tool or technological gadget that aims to increase the capacities of the visually impaired, promoting a greater independence ${ }^{(6)}$. Calling attention to the use of technology in the area of health, the nurse, as the professional that is responsible for health education, is also responsible for creating diverse strategies in the area of work, with an objective of building the interaction, and then transforming health assistance into a more dynamic activity ${ }^{(18-19)}$.

\section{CONCLUSION}

Through the reports, it can be seen that the AT was considered adequate by the visually impaired women. Therefore, we believe that the AT developed here was able to assist the needs of the visually impaired in this area of discussion. According to the perception of the participants, it was able to transmit understanding regarding STD, the female anatomy and the use of female condoms in a creative, interactive and effective way.

There is a need to develop some resources that assist the transmission of understanding about STD and the female condom to the visually impaired women, as they are clearly at a disadvantage in relation to available material regarding this theme in comparison to sighted people. Information is essential to the visually impaired if they are to have a safe sexual practice because, as any other women, they are also exposed to STD.

Sexual health education must be done more frequently for the visually impaired population, in order to deconstruct the prejudice they feel from their families and society in regards to their own sexuality. It is expected that this initiative will encourage health professionals to perform health education including visually impaired people and their sexuality, so that there is more inclusive education and a healthier clientele.

It is important to motivate them to use the female condom, as well as to disseminate the information regarding this tool, and also explain its use for visually impaired women, in order to create the conditions for them to exercise self-care towards their sexual and reproductive health, contributing to their autonomy.

Health professionals must improve assistance to this clientele, as the visually impaired reported the inadequate preparedness of the professionals while caring for them. They complain that they should be cared for as well as sighted people. On this basis, it can be seen that it is necessary to include courses in the health curriculum, a subject related to the healthcare service provided to this part of the population.

The AT developed here can be used by health professionals, and also in special and regular schools, with the objective of teaching sexual education from adolescence, so that they do not use any sexually risky behavior, but instead have safe sexual practice in the future.

It is necessary to recognize the limitations of this study, as it was performed with visually impaired women who already knew each other, which may have interfered in the group dynamics. However, the discourse from one of them did not influence the ideas of others, as there was an individual evaluation in separate rooms. Moreover, there were a reduced number of participants and a considerable difference in the level of education among the women.

It is necessary to have a more insightful and deeper evaluation of the AT by specialized referees and by a larger group of visually impaired volunteers. This new study is already being per- 
formed by the AT, aiming to be widely publicized among visually impaired people.

\section{REFERENCES}

1. Instituto Benjamin Constant [homepage in the internet]. Deficiência Visual [cited 2010 May 5]. Available from: http://ibcserver0c.ibc.gov. $\mathrm{br} /$ ?itemid=93\#more.

2. Soares AHR, Moreira MCN, Monteiro LMC. Jovens portadores de deficiência: sexualidade e estigma. Ciênc saúde coletiva. 2008; 13(1):185-94.

3. Sousa FS, Baptista RS, Coura AS, França EG, Pagliuca LMF, França ISX. Sexualidade das pessoas com deficiência ( $P C D)$ e a vulnerabilidade à aids: revisão sistemática de literatura. Online braz j nurs [Internet]. 2009 [cited 2010 Apr 12]; 8(3):[about 6 p.]. Available from: http://www. objnursing.uff.br/index.php/nursing/article/ view/j.1676-4285.2009.2566/html_51.

4. Paula AR, Sodelli FG, Faria G, Gil M, Regen M, Meresman S. Pessoas com deficiência: Pesquisa sobre a sexualidade e vulnerabilidade. Temas desenvolv. 2010; 17(98):51-65.

5. Santos $C L$, Pessoa IN, Pereira PFQ, Ferreira TF. Preservativo feminino: uma nova perspectiva de proteção. Rev enferm UERJ. 2005; 13(2):270-4.

6. Bersch R. Introdução à tecnologia assistiva. Porto Alegre: CEDI;2008.

7. Cezario KG, Mariano MR, Pagliuca LMF. Comparando o comportamento sexual de cegos e cegas diante das DSTs. Rev eletr enferm [Internet]. 2008 [cited 2010 Jan 30]; 10(3):686-94. Available from: http://www.fen.ufg.br/revista/v10/n3/v10n3a14. htm.

8. Camargo EAl, Ferrari RAP. Adolescentes: conhecimentos sobre sexualidade antes e após a participação em oficinas de prevenção. Ciênc saúde coletiva. 2009; 14(3):937-46.

9. Cezário KG. Avaliação de tecnologia assistiva para cegos: enfoque na prevenção ao uso de drogas psicoativas. Fortaleza. Dissertação (Mestrado em enfermagem) - Universidade Federal do Ceará; 2009.

10. Oliveira PMP. Avaliação de Tecnologia Assistiva sobre amamentação para pessoas cegas. Fortaleza. Dissertação (Mestrado em enfermagem) - Universidade Federal do Ceará; 2009.

11. Bardin L. Análise de Conteúdo. 5. ed. Lisboa: Edições 70; 2008.

12. Ministério da Saúde. Caderneta de saúde da adolescente. Brasília: MS; 2009.

13. Moura GR, Pedro ENR. Adolescentes portadores de deficiência visual: percepções sobre sexualidade. Rev latinoam enferm. 2006; 14(2):220-6.

14. Pagliuca LMF, Cezário KG, Mariano MR. A percepção de cegos e cegas diante das drogas. Acta paul enferm. 2009; 22(4):404-11.

15. Pontes AC, Leitão IMTA, Ramos IC. Comunicação terapêutica em Enfermagem: instrumento essencial do cuidado. Rev bras enferm. 2008; 61(3):312-8.

16. Bites PG, Almeida OCS. Design de Interação para WEB com ênfase em Pessoas com Deficiência [article in the Internet]. 2009 [cited 2010 Ago 11]. Available from: http://www.abed.org.br/congresso2009/CD/trabalhos/1552009195745.pdf

17. Macêdo KNF, Pagliuca LMF, Almeida PC, Cardoso MVLML, Rebouças CBA. Aspects of verbal communication between nurses and visually impaired people. Rev RENE. 2009; 10(2):29-36.

18. Pagliuca LMF, Oliveira PMP, Rebouças CBA, Galvão MTG. Literatura de cordel: veículo de comunicação e educação em saúde. Texto contexto enferm. 2007; 16(4):662-70.

19. Oliveira PMP, Rebouças CBA, Pagliuca LMF. Construção de uma tecnologia assistiva para validação entre cegos: enfoque na amamentação. Rev bras enferm. 2009; 62(6):837-43.

Received: 31/07/2012

Revised: 06/06/2013

Approved: 06/08/2013 